\title{
Future changes and uncertainty in decision-relevant measures of East African climate
}

\author{
F. Jorge Bornemann ${ }^{1}$ - David P. Rowell ${ }^{1}$ (D) Barbara Evans ${ }^{2} \cdot$ Dan J. Lapworth ${ }^{3}$. \\ Kamazima Lwiza ${ }^{4}$ - David M.J. Macdonald ${ }^{3}$ • John H. Marsham ${ }^{2,5} \cdot$ Kindie Tesfaye $^{6}$. \\ Matthew J. Ascott ${ }^{3} \cdot$ Celia Way $^{2}$
}

Received: 18 July 2018 / Accepted: 10 July 2019 / Published online: 29 July 2019

(C) The Author(s) 2019

\begin{abstract}
The need for the development of adaptation strategies for climate change in Africa is becoming critical. For example, infrastructure with a long lifespan now needs to be designed or adapted to account for a future climate that will be different from the past or present. There is a growing necessity for the climate information used in decision making to change from traditional science-driven metrics to decision-driven metrics. This is particularly relevant in East Africa, where limited adaptation and socio-economic capacity make this region acutely vulnerable to climate change. Here, we employ an interdisciplinary consultation process to define and analyse a number of such decision-oriented metrics. These metrics take a holistic approach, addressing the key East African sectors of agriculture, water supply, fisheries, flood management, urban infrastructure and urban health. A multifaceted analysis of multimodel climate projections then provides a repository of user-focused information on climate change and its uncertainties, for all metrics and seasons and two future time horizons. The spatial character and large intermodel uncertainty of changes in temperature and rainfall metrics are described, as well as those of other relevant metrics such as evaporation and solar radiation. Intermodel relationships amongst metrics are also explored, with two clear clusters forming around rainfall and temperature metrics. This latter analysis determines the extent to which model weights could, or could not, be applied across multiple climate metrics. Further work must now focus on maximising the utility of model projections, and developing tailored risk-based communication strategies.
\end{abstract}

\section{Introduction}

East Africa is particularly vulnerable to extreme weather and climate events, due to a socioeconomic situation characterised by limited resources and low adaptation capacity. This was

Electronic supplementary material The online version of this article (https://doi.org/10.1007/s10584-01902499-2) contains supplementary material, which is available to authorized users.

David P. Rowell

dave.rowell@metoffice.gov.uk

Extended author information available on the last page of the article 
recently highlighted for example by the extensive devastating impact of 2006 floods and 2010-2011 drought (e.g. Hillbruner and Moloney 2012; Nicholson 2017). A large portion of the rural economy - currently representing $75 \%$ of the population-is agricultural, $80 \%$ of which is smallholder production (Salami et al. 2010; Muyanga and Jayne 2014) with consequential high vulnerability (Niang et al. 2014; Nakawuka et al. 2017). Natural resources are also under pressure from an increasing population with regional constraints on water availability (Calow et al. 2010; MacDonald et al. 2012), and stocks for alternative livelihoods such as fisheries (LVFO 2016).

Rapid urbanisation is another feature of East Africa, with the share of the urban population increasing from 21 to $27 \%$ during 2000 to 2015, and expected to reach $34 \%$ by 2030 (UNDESA 2018). This inevitably increases pressure on urban infrastructure, particularly drainage and sanitation, reducing spare capacity and augmenting the consequences of floods and their associated health hazards when sanitation infrastructure fails. At the same time, the fast pace of urban growth and relatively weak financial base of many urban administrations present challenges to the planning and delivery of services which rely on infrastructure that typically has a design life measured in decades (Arisz and Burrell 2006; Bieker et al. 2010).

The effects of climate change are thus potentially disastrous for East Africa. It is therefore imperative that full and tailored information are available from climate projections to decision makers, within a framework that enables prioritisation of climate-resilient development, utilising cost-effective measures to tackle risks. There is a need to transition from traditional science-oriented climate metrics to decision-oriented climate metrics that can be employed more directly for risk assessment and management. We define such 'decision-oriented climate metrics' as a statistical measure of an aspect of climate that may change in the future, and is thought to be relevant for assessing vulnerabilities to high-impact climate events.

To enable the identification of metrics which are usefully oriented towards decision making, it seems self-evident that expertise must be drawn from both climate science and those sectors where such decisions are made. In addition, most sectors are highly interconnected (for example, agriculture in East Africa is strongly influenced by groundwater and surface water availability as well as by rainfall) with multiple climate drivers also interacting. Thus, engagement between experts across a range of sectors (multidisciplinarity) and codevelopment of new approaches (transdisciplinarity) is required. The HyCRISTAL project (Integrating Hydro-Climate Science into Policy Decisions for Climate-Resilient Infrastructure and Livelihoods in East Africa, Marsham et al. 2015, http://www.futureclimateafrica. org/project/hycristal/) provides such an engagement framework for East Africa, facilitating the necessary links between climate science, impacts modelling, advances in agriculture and engineering and social science to explore some key unresolved questions in each area (e.g. Conway et al. 2005; MacDonald et al. 2009; Rowell et al. 2015). The project is predicated on the understanding that the reach and utility of each of the disciplines, and especially their interdependences, must be maximised to realise the practical implementation of resilience enhancing measures.

In this study, we employ an interdisciplinary consultation process to produce a suite of decision-oriented climate metrics and analyse their projected changes and uncertainties with a view on the practical application of outcomes. We focus on metrics relevant to urban water, flooding and sanitation provision, and to rural livelihoods, all of which are important for East Africa, although noting that many are also applicable to other sectors and other regions of Africa. This will contribute to the foundations of other studies that will utilise the output of the impact models forced by the climate projections analysed here. 
Section 2 describes the approach and defines the decision-oriented climate metrics with their root in current and projected vulnerabilities. Section 3 describes the analysis techniques and data. Section 4 presents the projected changes in metrics and their uncertainty, inferring the potential risks associated with these. Section 5 explores intermodel correlations between the metrics to identify interdependencies that have the potential to help better understand and reduce uncertainty. We then conclude in section 6 , including discussion of the implications of our findings, and further work that must follow this study.

\section{Characterisation of decision-relevant metrics}

The identification of critical decision-oriented climate metrics was based on a two-step modified form of Delphi consultation, each step involving several rounds of consultation with panels of sector experts and climate scientists (Garcìa and Suàrez 2013). Two steps were required to first identify a set of relevant climate-sensitive impact sectors and then identify metrics for these priority sectors. The first step, between June and December 2014, was structured to identify critical climate-sensitive sectors for inclusion in the project as a whole. Rounds of consultation were organised with experts working in East Africa, with a focus on countries in the Lake Victoria Basin. Participants were identified through a cascade approach, with two broad areas of focus: rural development and urban infrastructure. Around 20 experts were consulted and the process resulted in the identification of six focus sectors (agriculture, water supply, lake fisheries, pond fish farming, flood management and urban infrastructure). The contrasting climate sensitivities of these sectors are expanded below.

The second step involved the identification of key decision-relevant metrics for each sector. This was initiated in September 2015 in Kampala at the launch workshop for the HyCRISTAL project and involved a structured engagement with 29 partners from six countries, including practitioners, engineers, agronomists, fisheries experts, economists and development specialists (Marsham et al. 2015). Preliminary results were processed and reviewed by the project team and then refined in a second round of telephone and Web-based discussions with panels selected to provide expertise on the six focus sectors.

The final step was to review and agree on the selected sectors and the proposed key metrics (see below) at the HyCRISTAL annual meeting held in Kampala in April 2018, which included 30 partners, from six countries.

This process considered a number of decisions currently being taken that will impact East African livelihoods over the next few decades, which are partly dependent on climate change information for that period (Table 1, central column), for example the specification of the size of a drainage channel or the selection of suitable crop species. We then determined the climaterelevant phenomena that affect these decisions, e.g. the severity and duration of rainfall events or water stress on crops. We also considered how the acquired climate information would be used - both directly and indirectly via impacts modelling - which then enabled us to hone this descriptive information to appropriate statistical measures, for example the change in the 99th percentile of daily precipitation or the change in the annual cycle of evaporation. By following a structured multidisciplinary approach, experts from different sectors collaborated with climate scientists to generate a refined list of critical decision-relevant metrics which take into account data availability, statistical processing and the level of detail needed; summary outcomes appear in Table 1, the definition and parameters of each metric in Table 2 and full outputs of the second step discussions in Table.Supp.1. The resultant metrics exhibit some 
similarities with those often used by climate scientists (e.g. Sillmann et al. 2013), supporting the value of such studies, whilst our consultation process also adds value through additional metrics not otherwise foreseen and through the use of thresholds specific to our geographic and sector foci.

To underpin the above process, and evidence the linkages between sectoral issues and decision-oriented metrics, a brief description of the climate sensitivities of each sector follows.

Agriculture Yields are sensitive to both the mean and variability of climate, particularly precipitation and temperature. Future changes could potentially reduce crop productivity, with significant adverse impacts on food security (Niang et al. 2014; Tesfaye et al. 2015), through shorter growing periods, increased waterlogging, periodic reduced soil moisture availability and unfavourable temperature ranges (Thornton et al. 2014). On the other hand, irrigation can supplement water demands (Mueller et al. 2012) and extend productivity to the dry seasons; strategies must account for current water resources, climate change, abstraction potential and maintenance of environmental flows.

Water supplies As population increases, water demand-for both domestic and production uses - will rise. Strategic planning of water supplies will require projections of both surface water (Meigh et al. 1999) and groundwater resources (Carter and Parker 2009; Taylor et al. 2009; MacDonald et al. 2012). Climate variability and change influence the availability of surface and groundwater resources directly through changes in evaporation, runoff, soil moisture and recharge as well as through anthropogenic changes in water use and land use (Owor et al. 2009; Taylor et al. 2013a, b).

Fisheries (lake) Livelihood adaptation measures around Lake Victoria depend on changes in the lake ecosystems (water column structure, nutrients and productivity) which control the stocks of commercially important and other species. Rising surface temperatures can enhance stratification, leading to hypoxia (deoxygenation of bottom water; Paerl and Huisman 2008; Kling and Mugidde 2014). This is already increasing and is one factor affecting the formerly productive and species-rich demersal fish community (Hecky et al. 1994).

Fisheries (farming in ponds) Lake levels will be critical for informing the viability of fish farming in ponds mostly located in low-lying wetland areas near the lakeshore. The water balance in these ponds is controlled by flood events at the beginning of the season and by the precipitation-evaporation balance during the operational period (Kipkemboi et al. 2007). There is thus a strong relationship between the operation of near-shore ponds, lake levels and climatic indices of drought and rainfall (Awange et al. 2008).

Flood management and urban infrastructure The future frequency of both flash floods and more persistent and widespread fluvial flood events depends on changes in the intensity and duration of rainfall. The growing population will be more vulnerable, particularly where it is forced to occupy flood-prone land. Householders are affected through loss of assets (primarily housing) and failure of infrastructures including sanitation, drainage and road access (Douglas et al. 2008; Douglas 2017). Substantial investment is required (Di Baldassarre et al. 2010), including ensuring that standards for the design and construction of infrastructure and flood mitigation systems are adapted to the changing characteristics of precipitation. 


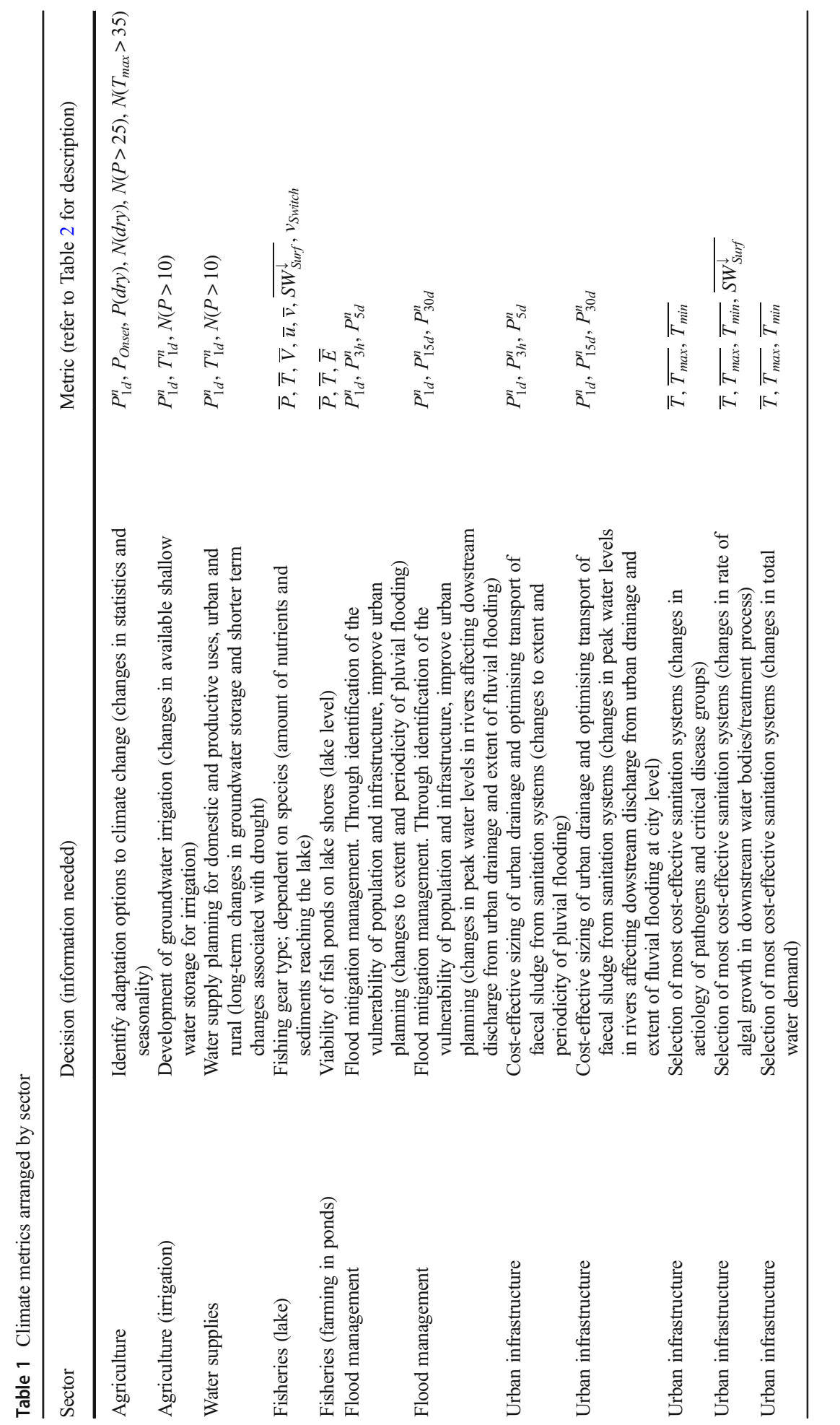




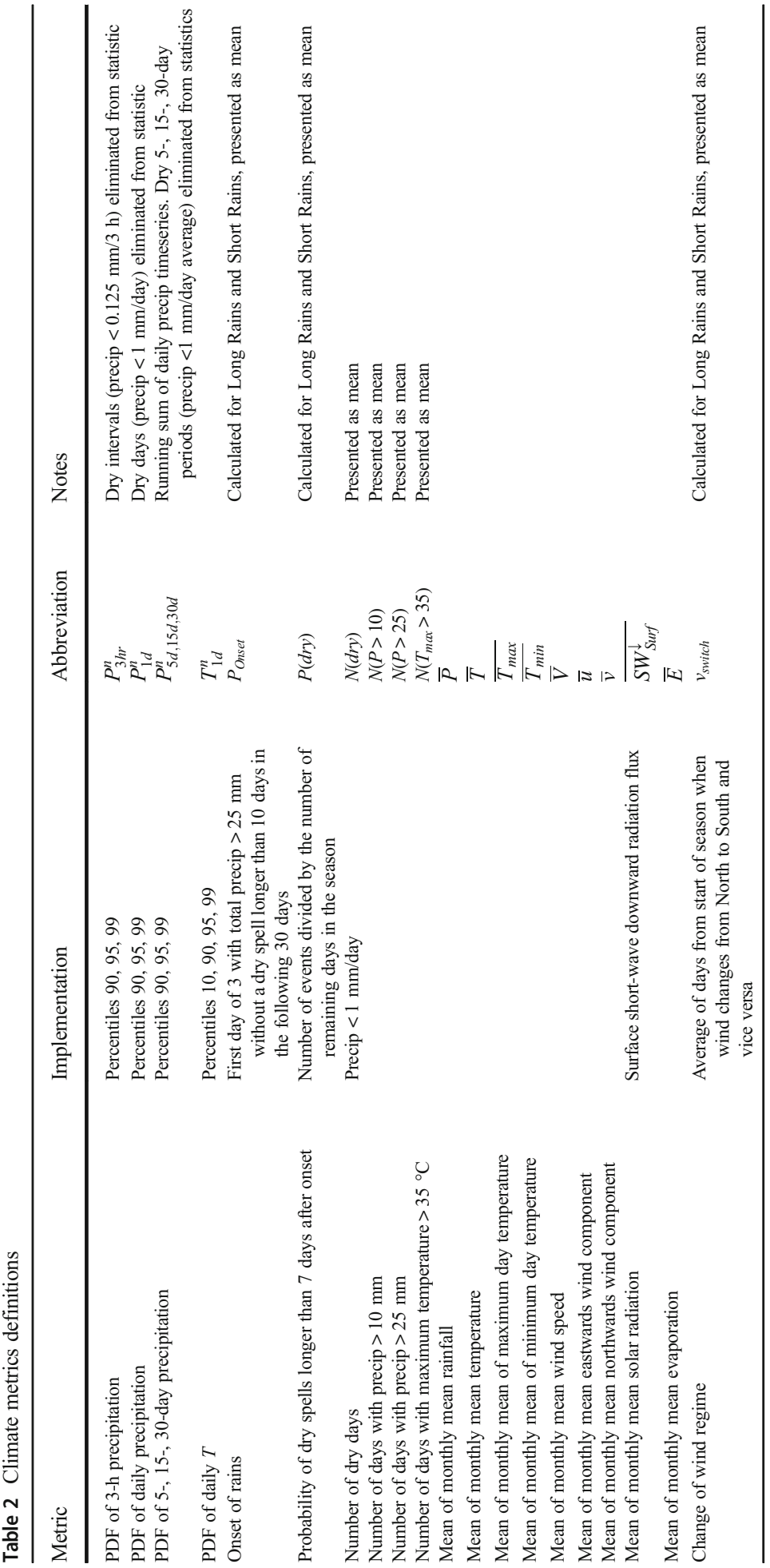


Urban infrastructure (health) Changes in temperature and solar radiation impact the growth rate of algae in downstream water bodies which receive nutrient-rich sanitation overflows. This has knock-on effects on water quality in rivers and lakes and on the effectiveness of water treatment. Temperature rises may also impact disease aetiology and change the rate, infectivity and spread of sanitation-related and drainage-related diseases under conditions of flooding and sanitation failures (Hunter 2003; Patz et al. 2005; McMichael et al. 2006).

\section{Data and further methodology}

This study uses historical simulations and future projections from the database of global climate models contributing to phase 5 of the Coupled Model Intercomparison Project (CMIP5; Taylor et al. 2012), focusing on the emissions scenario 'representative concentration pathway 8.5' (Riahi et al. 2011). This multimodel approach is essential in order to capture the large extent of projection uncertainty due to a variety of legitimate approaches towards formulating the range of critical processes within the climate system (see e.g. Flato et al. 2013 for a broad perspective, or Rowell and Chadwick 2018 for a more detailed East African perspective). Nevertheless, in utilising this data, we acknowledge that these models share certain characteristics - such as the parametrisation of convection or policy assumptions affecting aerosol emissions (Finney et al. 2019; Kendon et al. 2019; Scannell et al. 2019 manuscript submitted) - that limit their projections, and so parallel research is underway that will integrate such knowledge with CMIP projections.

Since new infrastructure and local mitigation strategies will remain in place for the medium to long term (here defined as 5 to 40 years), and national development plans in East Africa operate over this broad timeframe (e.g. Uganda Vision 2040), metrics are calculated over the future time slice 2040-2059. This period is the focus of all results presented in the main body of this paper. However, 3-hourly rainfall data is often not available for this period, so where this metric is addressed in Supplementary Material, analysis is restricted to an earlier 2020 2039 period. For its long duration to minimize sampling uncertainty, and prior to the 2005 enddate of the historical simulations, 1950-1999 is chosen for the historical period. When several ensemble members are available for a model, only the first is used here for consistent sampling with those that have only one member.

Raw model data are interpolated using a conservative scheme to a common grid of $2^{\circ}$ latitude by $2^{\circ}$ longitude, chosen as being approximately the median resolution of models. For geographic averages, sea points are eliminated so that the analysis focuses on land, where our chosen metrics have relevance.

Seasonality is a key feature of the East African climate, described for example by Yang et al. (2015). For this study, the regions' semi-arid character and bi-modal precipitation distribution are imperative, with wet seasons occurring between March and May (MAM), named the "Long Rains", and between October and December (OND), named the "Short Rains", separated by dry seasons not exceeding $2 \mathrm{~mm} /$ day on average between June and September (JJAS) and in January-February (JF). As well as annual results, we use a seasonal stratification of MAM for the Long Rains, OND for the Short Rains and JJAS and JF for the dry seasons. Some metrics are also stratified by month.

The availability of the necessary variables to calculate each metric differs across models. Figure 1 shows the models that contribute to each metric, with full details freely available in each model's metadata. 


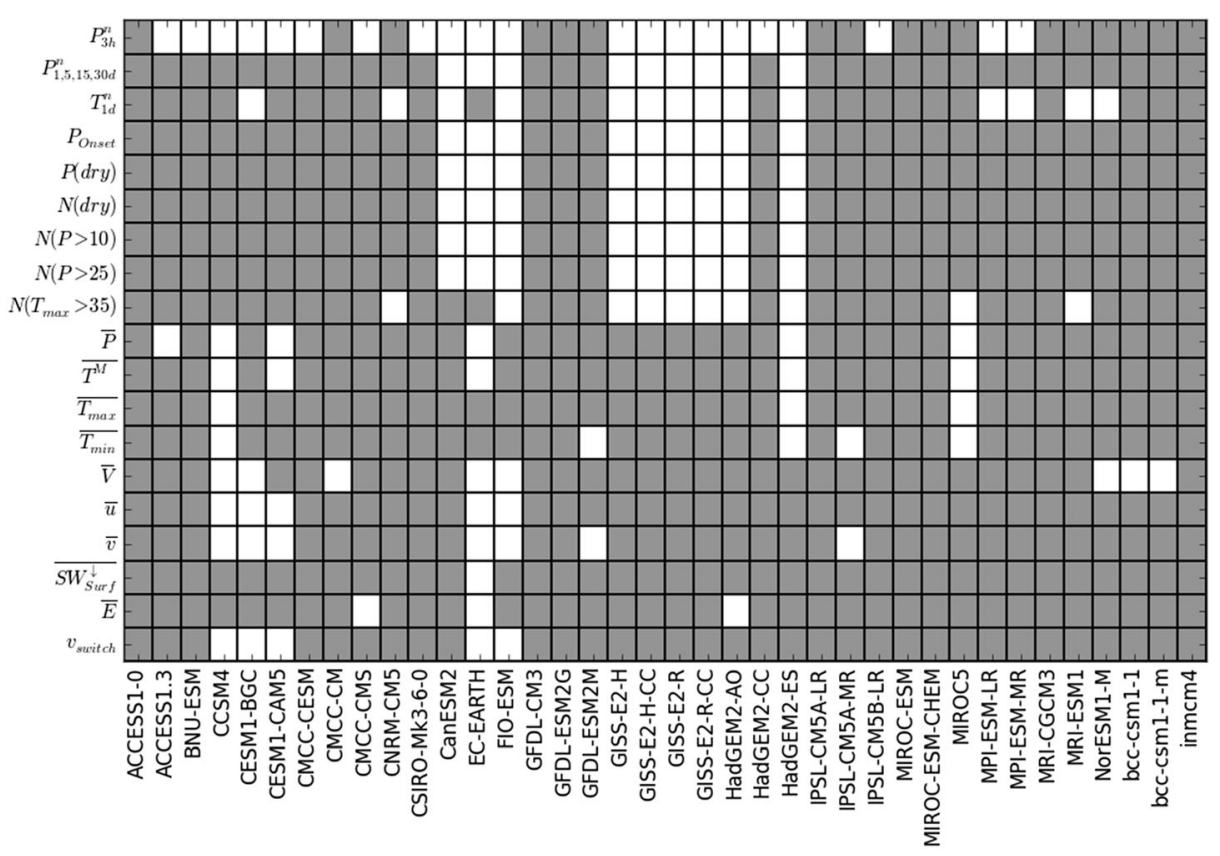

Fig. 1 Inventory of models and their contribution to metrics. Grey shade indicates that the model contributes to the metric

\section{Projected climate change in decision-relevant metrics}

A full analysis of the changes and uncertainties in all decision-relevant metrics over East Africa is provided in the Electronic Supplementary Material, with a sample of 6 metrics shown in Fig. 2. These form a first attempt at provision of user-relevant information on the models' climatological context, their projected changes and their uncertainty in these projections. The first column shows the models' historic average. Columns 2 and 3 map the projection uncertainty by ranking the change from all contributing models at each gridbox, and plotting the 10th and 90th percentiles of this distribution across models, i.e. the 10th and 90th percentiles in model space. This shows the range of plausible outcomes using the ensemble of models, steering users away from a likely misleading single deterministic interpretation, commonly based on the ensemble mean. Note that the choice of percentiles is somewhat arbitrary (an alternative might be to plot the full range, for example), and also that the models contributing to each tail differ between gridboxes. In practice, this approach was presented to users as the approximate upper and lower limits of the 'plausible range', followed by a very brief clarification of the computation in model space for those interested in the precise definition; the former at least was understood by stakeholders. Column 4 shows box-andwhisker plots of projected change across all models at 8 representative locations providing a further perspective on uncertainty (these are as follows: northern South Sudan, northern Uganda, southern Ethiopian Highlands, Kenyan Highlands, Lake Victoria, eastern Congo Basin, Tanzania plateau and Tanzania lowlands). Feedback requested from users at the Kampala meeting in April 2018 found there to be at least broad understanding and acceptance of these presentational approaches, although we stress that alternatives may be required for different audiences. 

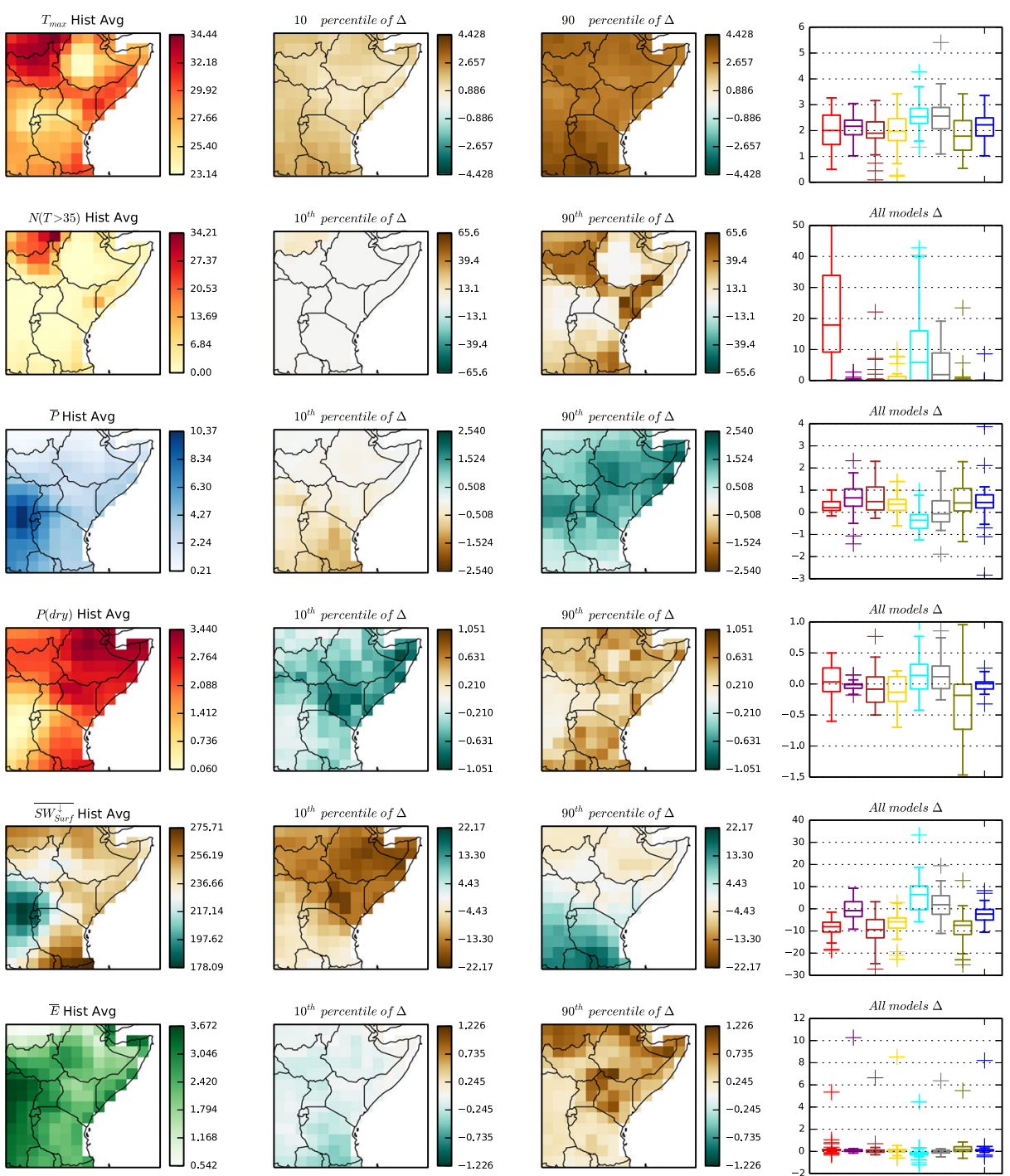

Fig. 2 Sample of geographical plots for exemplar metrics (OND, 2040-2059 horizon). See text for description of columns. Metrics in row, from top to bottom: monthly mean of daily max temperature $\left({ }^{\circ} \mathrm{C}\right)$, number of days with maximum temperature exceeding $35^{\circ} \mathrm{C}$, monthly mean precipitation $(\mathrm{mm} /$ day), probability of dry days, monthly mean of shortwave downward radiation flux at the surface $\left(\mathrm{W} / \mathrm{m}^{2}\right)$, monthly mean evaporation $(\mathrm{mm} /$ day). Regions represented in box and whisker plots, from left to right: South Sudan, North Uganda, Ethiopian Highlands, Kenyan Highlands, Lake Victoria, Congo Basin, Tanzania plateau, Tanzania lowlands, with locations shown in the Supplementary figures

A description of the key findings follows, but stressing that their applicability depends on the sectors and decisions they will inform. The overall picture of a warming climate with uncertain rainfall changes is of course expected. But the details presented here have real value in showing metrics which have been co-produced with users, and with a presentation oriented to users emphasising the range rather than the mean. 
Unsurprisingly, temperature is consistently projected to increase throughout the region, with uncertainty relating to the magnitude of change (Fig. 2, row 1). The distribution of projected change across models is also geographically uniform, and similarly uniform through the annual cycle (Fig.Supp.1). The lower-right panel of Fig. 3 also shows a broadly uniform shift in the distribution of daily temperatures, i.e. similar increases in the median and tails, with the ACCESS1.3 model result (top right) being typical of the majority of models. This implies a lack of feedback that could amplify heatwaves more than the mean, which should however be viewed with caution due to the limited resolution of these large-scale models: low resolution in particular limits the representation of absolute values of current climate metrics over fine-scale orography, and so is also likely to limit the projected anomalies of such metrics for similar reasons. Changes in the number of days exceeding $35^{\circ} \mathrm{C}$ is also consistently positive (Fig. 2, row 2), including the possibility of dramatic increases (90th model percentile), mainly restricted to already hot low-lying areas (within the limits of model resolution).

Rainfall metrics present a more complex picture. Overall, models suggest a more likely projected increase in the wet season total rainfall (Fig. 2, row 3), as well as in metrics that quantify the 90th percentile of rainfall accumulated over 3-h, daily, and 5-day and 15-day periods (Fig.Supp.2). The latter is consistent with a tendency to stretch the high tail of the daily rainfall distribution (Fig. 3, left-hand panels), suggesting that rainfall increases will be mostly accounted for by heavier short duration events over several hours or days. New research suggests that global models likely underestimate this high tail stretch (Kendon et al. 2019), information that we have also passed to stakeholders. Despite these overall consistencies
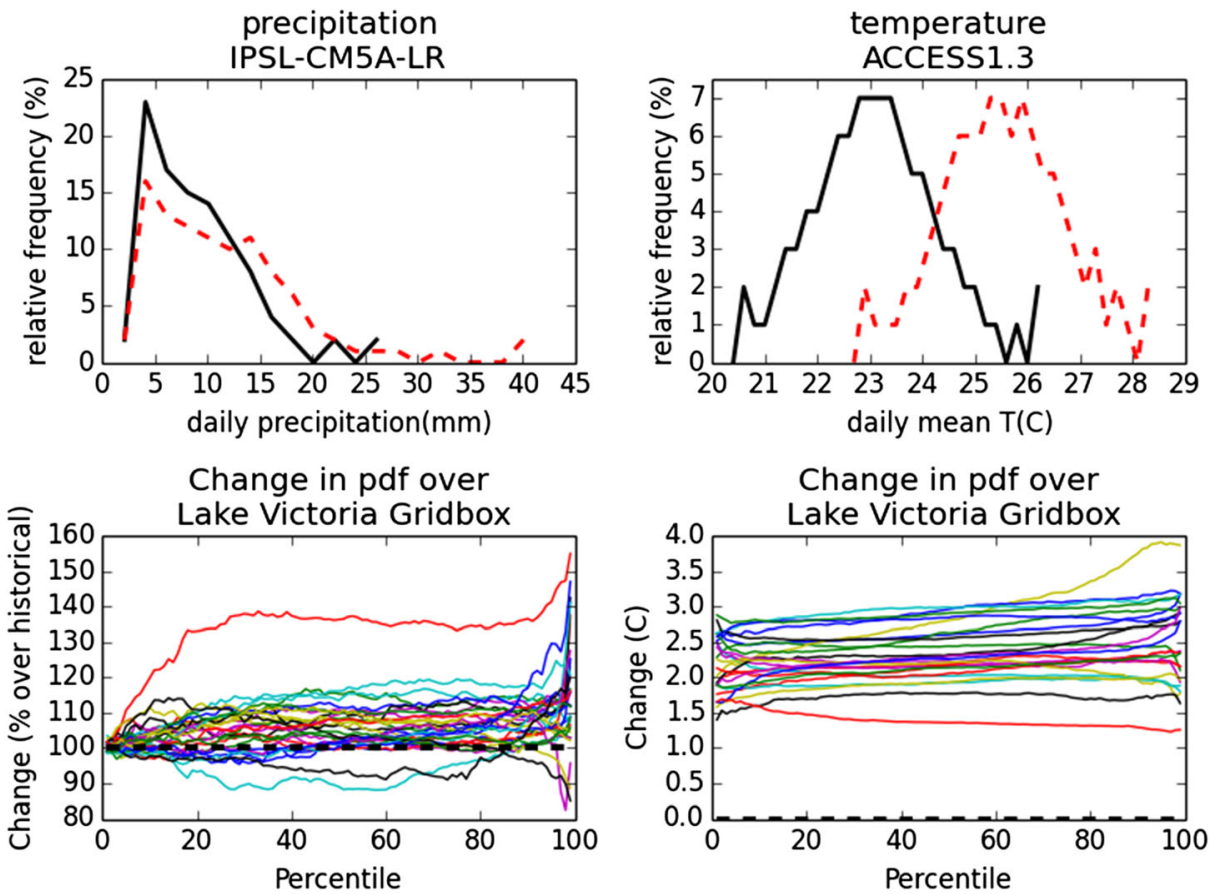

Fig. 3 Top row, pdf of historical (black solid) and 2040-2059 projection (red dashed) on the whole year for representative models. Bottom row, changes in the pdf on all models 
amongst metrics and models, there are also noticeable disparities between models, for example the seasonal mean box-and-whisker plot in Fig. 2 incorporates projections of both decreasing and increasing rainfall. Differences between the two wet seasons are also notable, with the suggestion that changes may be largest during the Short Rains (Fig.Supp.3).

Further comments on rainfall-related metrics are as follows. Changes in the probability of dry days have large spatial and intermodel variability in both sign and magnitude (Fig. 2, row 4). Since these changes are absolute, they tend to be largest where current climate dry day probabilities are already high, and so the model's current climate spread will partly explain the intermodel spread in the magnitude of change, although not the variations in sign. The number of days with precipitation over $10 \mathrm{~mm}$ has strong seasonal and regional variabilities, with OND (Fig.Supp.4) showing a north-south split, whereby there is an increase in the northern half (a bimodal regime including an OND wet season) and a decrease in the southern half (more rain in boreal winter), and widespread amongst models. This contrasts with projected changes in the number of days with precipitation over $25 \mathrm{~mm}$, with most of the models predicting an increase in both MAM and OND for the whole region, although most accentuated over the Congo Basin and the Ethiopian Highlands where rainfall is already high (Fig.Supp.5,6).

Finally, projections for surface solar radiation exhibit a strong geographic split, with mostly decreases in the north and increases in the south (Fig. 2, row 5), consistent with the rainfall change (row 3). Evaporation tends to increase, and there is also a large positive outlier that demands further research (Fig. 2, row 6).

\section{Relationships between metrics}

Understanding how metrics relate to each other across the model ensemble is also valuable. For example, we might expect that models with a high change in one metric are also those that tend to have a high change in another metric, or vice versa. In this case, when further studies develop understanding of model performance for one of these metrics, or even develop a set of model weights, then the same insights or weightings could also be applied to the other metric, on condition that physically robust arguments can be put forward to explain this intermetric relationship. Alternatively, in a reverse thought process, strong intermodel correlations within metric pairs may point to physical relationships in climate models, promoting further research into the models' viability. The strength of such physical relationships is unclear a priori, and likely varies regionally, e.g. due to potentially different temporal and mechanistic processes that drive changes in short-term extremes versus seasonal means (cf. Taylor et al.'s 2017 analysis of Sahel rainfall, for example), leading to different intermodel variabilities.

These intermodel (cross-ensemble) correlations between metric pairs are shown in Fig. 4 for a representative subset of metrics, removing those that we opined a priori would be very strongly correlated, simply to reduce the size of the resultant matrix. The matrix elements are maps of Pearson's correlation coefficient $(r)$ for projected changes to the Long Rains at the 2040-2059 horizon and for an area centred on Lake Victoria. Correlations are computed separately at each gridbox, with the sample for each pair determined by the models common to both metrics (see Fig. 1).

The strongest correlations (typically $r>0.9$ ) are between $\overline{T^{\max }}, \overline{T^{\min }}, \bar{T}$ and $T_{1 d}^{90}$, the latter being consistent with the median and tails of the distribution of temperatures changing by approximately the same amount. For metrics based on rainfall, there are significant positive 


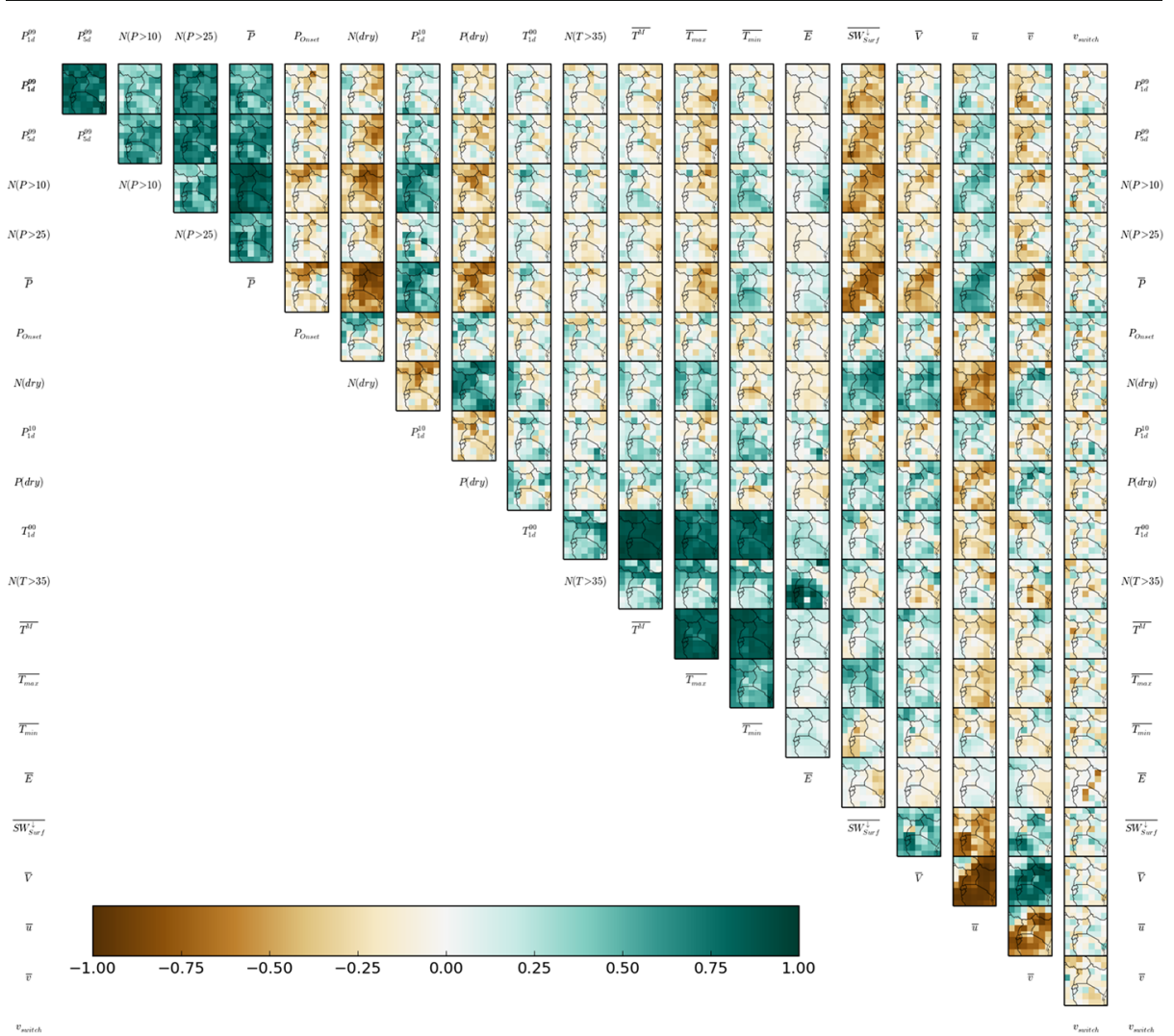

Fig. 4 Pearson's $R$ correlation coefficient between metrics pairs on a sub-area of the analysis grid centred on Lake Victoria for the MAM season and 2040-2059 horizon

correlations between $P_{1 d}^{90}, P_{5 d}^{90}, \bar{P}, N(P>10)$ and $N(P>25)$, indicating that in the models, in this region, either changes in the monthly means are dominated by changes in the distribution of (sub)daily rainfall, or that changes in the same large-scale processes affect rainfall events of all magnitudes. Intermodel variations of these rainfall-derived metrics are largely independent of those derived from temperature, but instead exhibit some anticorrelation with $\overline{S W_{\text {Surf }}^{\downarrow}}(r \sim-0.5)$, inferring an impact of related changes in cloud cover. Conclusions are similar for the Short Rains (Fig.Supp.7).

The interrelationships of Fig. 4 are summarised for both rainy seasons in Fig. 5, showing how metrics cluster according to the consistency amongst metrics in the relative behaviour of their modelled changes across the ensemble. Absolute correlations for all metric pairs are first averaged over the domain of Fig. 4. We define values above 0.75 as 'strongly correlated', values in the range 0.50 to 0.75 as 'moderately correlated' and values below 0.5 as potentially uncorrelated (inevitably these thresholds are somewhat arbitrary, but have been chosen to be round numbers falling close to the boundaries for 50\% common variance [0.707] and statistical insignificance at the 5\% level [0.43 for 20 independent models]). All strongly correlated metric pairs are allocated to the same cluster (ellipses in Fig. 5), with the addition of other metrics on condition that they are strongly correlated with at least one other metric in the cluster (note, there are no metrics that are both uncorrelated and strongly correlated with other metrics). 
Moderately correlated metric pairs (and not strongly correlated with any other metric) are represented by adjacent ellipses if they derive from the same variable type (i.e. rainfall), or by line connections for differing variable types.

Three main clusters of significant correlation/anti-correlation are apparent, marked by different colouring in Fig. 5. The first groups the rainfall metrics, and consists of two subclusters with (a) daily rainfall exceeding $25 \mathrm{~mm}$ and the 99th percentile of daily or 5-day rainfall, and (b) monthly mean rainfall and the number of days with rainfall exceeding $10 \mathrm{~mm}$. These sub-clusters are less strongly linked in terms of intermodel behaviour, and also less strongly linked with the 10th percentile of daily rainfall and the number of dry days, the latter of which in turn somewhat correlates with the probability of dry days. The exception in terms of rainfall is change to onset date, which is uncorrelated with other rainfall metrics, and indeed is likely governed by different physical processes and so ranks differently amongst models. The second main cluster groups all but one of the temperature metrics (monthly mean, monthly mean of the daily maxima and minima and 90th percentile of the daily mean), with the count
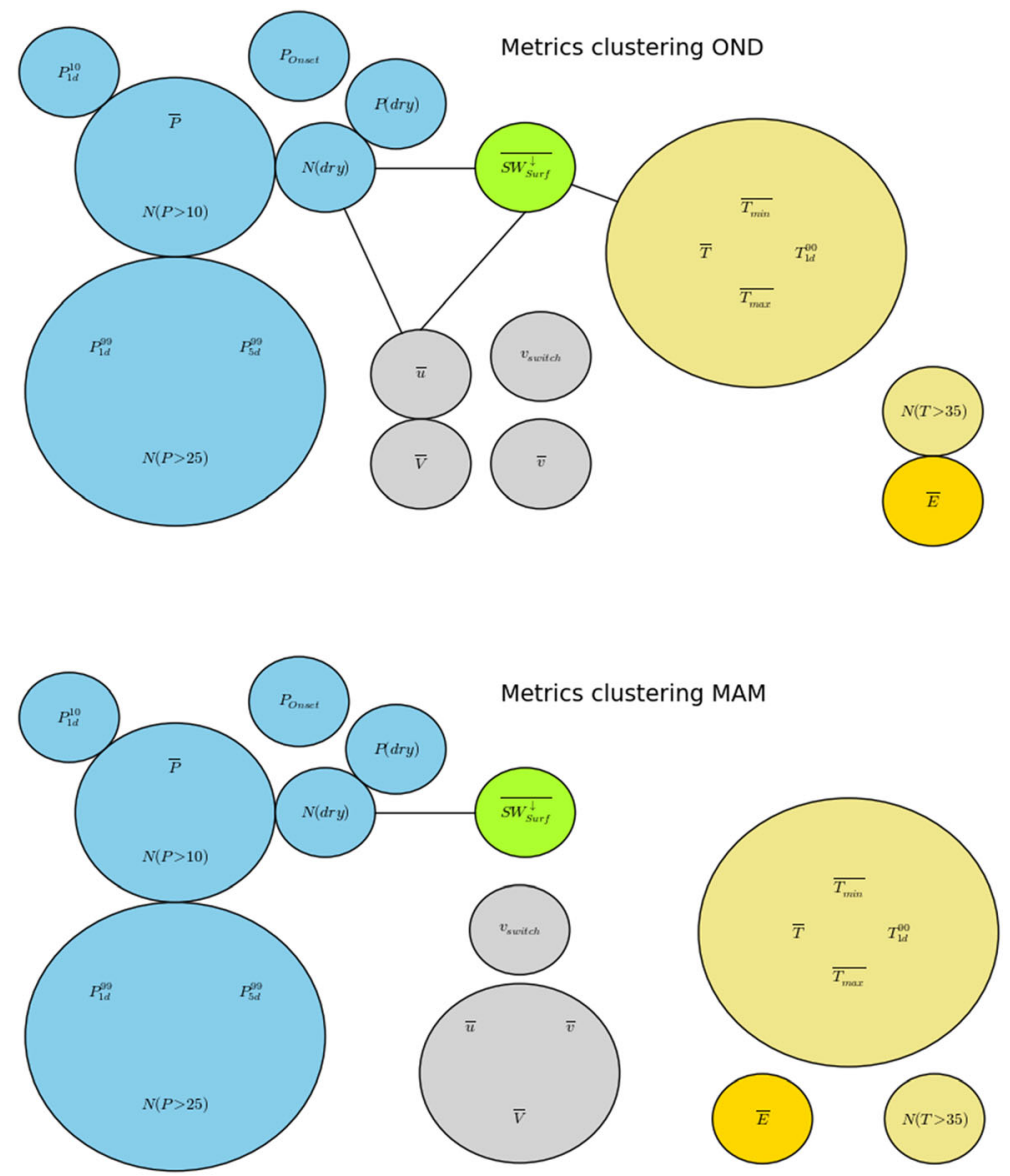

Fig. 5 Schematics of clustering of the main metrics using absolute value of correlations on the 2040-2059 horizon (OND top, MAM bottom). The most closely correlated metrics are within the same ellipse, with moderately correlated groups in adjacent ellipses (if the same physical variable) or by connected lines (if not). See text for details 
of days exceeding $35^{\circ} \mathrm{C}$ behaving differently across models, likely due to a strong dependence on the spatial pattern of climatological model errors (cf. Sect. 4). Third, wind-related metrics also show some correlation/anti-correlation with each other, with the strength of relationship dependent on season. A majority of links (and lack thereof) are consistent between the two wet seasons. Where they differ, this likely reflects sampling impacts close to a correlation threshold, and perhaps also the greater role of large-scale controls on the natural component of climate change in OND (e.g. Nicholson 2017).

\section{Discussion and conclusions}

We take an interdisciplinary approach to define a number of climate change metrics from a user-relevant point of view, to help provide decision makers with information relevant to their particular applications. A number of sectors are considered-agriculture, water supply, fisheries, flood management, sanitation and urban development - all of which are important for East Africa, and are sensitive to climate change. The process brought together climate scientists and sector specialists and to the best of our knowledge is one of the first attempts at a systematic co-identification of critical decision-oriented climate change metrics in East Africa. Significant effort was required for mutual understanding of perspectives, priorities and even vocabulary used by specialists across disciplines. However, an investment of time helped overcome these challenges, leading to a consensus on the suite of metrics developed here. Participants also reported a high level of satisfaction with the co-identification process which stimulated lively discussions.

Changes in these metrics and their uncertainties over East Africa have been computed from the CMIP5 multimodel ensemble and will provide the basis for further work. This includes assessments of the climate context behind CMIP5-driven impacts modelling, the exploration of communication tools to disseminate results to relevant stakeholders and the generation of impact metrics from the current climate-based metrics. Calculations are for 2040-2059 (or 2020-2039 where necessitated by data availability) relative to 1950-1999. We do not consider uncertainties other than those captured by the spread in CMIP5 models, e.g. from the changing future patterns of land use or aerosol emissions, or atmospheric processes not captured by the CMIP ensemble. We do not apply bias correction, which is valuable for applications in many specific contexts, but rather use a mixture of changes to absolute and relative thresholds to analyse changes relevant to decision makers, and explore the uncertainties and interrelationships in these changes.

Interpretation of results must be tailored to specific sectors and users, but some emerging signals are more widely relevant. Projected temperature changes are relatively homogenous across both spatial and temporal scales, but exhibit substantial uncertainty in magnitude. For rainfall, the signal is more mixed, varying geographically, but tends to be larger in the Short Rains season. There is an overall indication of an increase in the frequency of the most intense events, although agreement between models in terms of magnitude is poor.

Relationships between metrics have also been explored. Intermodel correlations between metric pairs show that temperature-derived metrics cluster strongly together, with rainfallderived metrics forming three sub-clusters focussed on either short or longer-period accumulations or wet season onset date. Interseasonal variations in these findings are less important. These clusters could then inform the extent to which model weights can be simultaneously applied across multiple climate metrics. The fact that metrics of extremes are closely tied to 
those of mean change is encouraging. This suggests changes in the extremes are tied to the mean to some extent, potentially simplifying the challenge of predicting changes in extremes. Alternatively, this may reflect that these models are missing key small-scale processes that affect the changes in extremes (e.g. representation of convection, Kendon et al. 2019).

Uncertainty in both magnitude and direction of change in some metrics presents challenges for the use of climate data in impact-facing decision making. Practitioners reported a good general understanding that climate science contains uncertainty, but the nature and implication of this are less well understood. Amongst non-climate science participants in our consultation, uncertainty in the magnitude of the change was generally well understood but uncertainty over the direction of change was reported to be both unexpected and challenging. When moving towards policy development, practitioners reported that 'uncertainty' can be interpreted as uncertainty about the fact of climate change itself. In summary, uncertainty about the nature of the uncertainty appears to amplify as discussion moves from the science, through impacts analysis to policy. This suggests the need for better communication and explicit training designed to provide the next generation of key decision makers with additional appropriate analytical and problem-solving skills. For example, with tailored training, agricultural extensionists could potentially support a wide range of local experimentation with cropping patterns and crop selection, in anticipation of a range of possible future scenarios, and provide bespoke advice as the future climate evolves, rather than rolling out a single approach supporting traditional cropping approaches. User-focussed communication approaches might include tools such as the subset of plausible climate risk narratives developed within HyCRISTAL (Burgin et al. 2019a, b), based on the metrics presented here as well as other sources including the concepts of Jack et al. (2019, manuscript submitted). Overall, the uncertainties point towards ensuring that long-term decisions are ideally robust to all possible futures, with flexible strategies that adapt as climate change signals emerge over the coming decades.

In the urban infrastructure context, notwithstanding the uncertainties in magnitude, it seems probable that the prevalence of significant flood events will increase. This provides a clear signal that improved sanitation systems - those that perform relatively better under flood conditions - are a good investment, along with improvements in the design, operation and maintenance of drainage systems. It also seems pragmatic that key infrastructures (bridges, culverts and key link roads) should be designed to higher standards due to their long life, critical interlinkages (e.g. between drainage and road access) and uncertainties in climate predictions. Some investments may also be more cost-effectively designed to 'fail safely' under a larger range of future climates, i.e. including the uncertain risk of extreme-impact events, to reduce investment costs today, while preparing for re-investment once the direction of climate change is more clearly understood.

In the context of fisheries, large future climate uncertainties pose a considerable challenge to the development of robust policies. For example, should fishermen be advised to invest in gear for Nile perch (hunters that thrive in clear water associated with a drier climate) or dagaa (that thrive in a wetter climate; Kashindye 2015)? The general direction of warming is clear, but uncertain details in its spatial pattern and lake depth profile are critical for changes in stratification and hence hypoxia. Rainfall also impacts eutrophication (via excessive nutrient input from runoff), as well as visibility (via sediment loading) affecting the reproductive behaviour of several species (Seehausen et al. 1997). Irrespective of these uncertainties, accurate determination of fish stocks, and their relative sensitivity to climate, overfishing and unchecked nutrient inputs, would be a pragmatic and immediate policy approach. 
Water supply planning is also challenging given uncertainties in projected annual rainfall. However, groundwater is able to effectively buffer interannual rainfall variability and is currently underdeveloped across East Africa (MacDonald et al. 2009; Altchenko and Villholth 2015). Despite the uncertainties in future recharge of the resource, investment to improve access to groundwater for rural communities and small towns is a no-regrets option. With a rapidly growing population, significant investment in higher capacity surface water storage infrastructure has been considered (Orindi and Murray 2005), although designs need to consider uncertainties in catchment water balance (Cole et al. 2014). The opportunities for and benefits of investment in irrigation infrastructure, both large and small scale, have been identified for East African agriculture, irrespective of climate change (You et al. 2011). Irrigation would be particularly valuable in areas where the probability of dry days is already high and likely to increase, as studies in the region have shown the limitation in agricultural production due to the uneven distribution of rainfall (Barron et al. 2003). However, the viability of the development of large-scale irrigation schemes in Sub-Saharan Africa has been questioned (Adhikari et al. 2015; Williams 2015), with small-scale irrigation, along with rainwater harvesting and soil water conservation methods, often promoted as more feasible options, especially for crop production in dry seasons (Kamwamba-Mtethiwa et al. 2016; Gowing et al. 2016).

Further work must now focus on understanding the sensitivity of the projected changes presented here to the inadequacies and missing processes in the CMIP5 multimodel ensemble, such as resolution, the representation of convection, and surface coupling. An in-depth understanding of the spread amongst models (Rowell and Chadwick 2018; Rowell 2019) also has the potential to reduce the substantial uncertainties identified in this analysis, although future consideration of other sources of uncertainty may increase the spread of possible futures considered. Our work has also highlighted the gap in understanding of the implications of climate change on immediate critical decisions amongst sectoral experts and stakeholders at national and local levels. Results derived from co-developed decision-relevant metrics represent an important first step, including the need to focus on the full range of plausible model outcomes rather than their ensemble mean. This approach can be replicated for other sectors and other geographic regions. Co-development of clear risk-based audience-dependent communication to stakeholders, of the anticipated changes in climate and its impacts, is then essential. Further publications will address each of these issues.

Acknowledgements The many modelling groups listed in Fig. 1 are gratefully acknowledged for producing and making their simulations available, as is the World Climate Research Programme Working Group on Coupled Modelling (WCRP-WGCM) for taking responsibility for the CMIP5 model archives, and the U.S. Department of Energy's Program for Climate Model Diagnosis and Intercomparison (PCMDI) for archiving the model output. Robert Wilby's comments on the manuscript were also much appreciated.

Author contributions FJB carried out the analysis, and FJB, DPR and JHM interpreted the results. MJA, BE, DJL, KL, DMJM, DPR and KT designed the decision-relevant climate metrics. DPR conceived the study with input from FJB and JHM. FJB and DPR wrote the paper, and all authors commented on the manuscript and contributed text.

Funding information This research was funded by the UK Department for International Development (DFID)/ Natural Environment Research Council (NERC) Future Climate for Africa (FCFA) HyCRISTAL project (NE/ M019985/1; NE/M020452/1). JHM was also funded by the NCAS ACREW project. 


\section{Compliance with ethical standards}

The views expressed do not necessarily reflect the UK Government's official policies. BGS authors publish with the permission of the Executive Director of the British Geological Survey (BGS-UKRI).

Open Access This article is distributed under the terms of the Creative Commons Attribution 4.0 International License (http://creativecommons.org/licenses/by/4.0/), which permits unrestricted use, distribution, and reproduction in any medium, provided you give appropriate credit to the original author(s) and the source, provide a link to the Creative Commons license, and indicate if changes were made.

\section{References}

Adhikari U, Nejadhashemi AP, Woznicki SA (2015) Climate change and eastern Africa: a review of impact on major crops. Food Energy Secur 4(2):110-132

Altchenko Y, Villholth KG (2015) Mapping irrigation potential from renewable groundwater in Africa-a quantitative hydrological approach. Hydrol Earth Syst Sci Discuss 19(2):1055-1067

Arisz H, Burrell B (2006) Urban drainage infrastructure planning and design considering climate change. In 2006 IEEE EIC Climate Change Conference. IEEE, pp. 1-9. Available at: http://ieeexplore.ieee. org/document/4057381/. Accessed 13 June 2018

Awange JL, Ogalo L, Bae KH, Were P, Omondi P, Omute P, Omullo M (2008) Falling Lake Victoria water levels: is climate a contributing factor? Clim Chang 89(3-4):281-297

Barron J, Rockström J, Gichuki F, Hatibu N (2003) Dry spell analysis and maize yields for two semi-arid locations in East Africa. Agric For Meteorol 117(1-2):23-37

Bieker S, Cornel P, Wagner M (2010) Semicentralised supply and treatment systems: integrated infrastructure solutions for fast growing urban areas. Water Sci Technol 61(11):2905 Available at: http://wst.iwaponline. com/cgi/doi/10.2166/wst.2010.189. Accessed 13 June 2018

Burgin L, Walker G, Cornforth R, Rowell D, Marsham J, Semazzi F, Sabiiti G, Ainslie A, Araujo J, Ascott M, Clegg D, Clenaghan A, Lapworth D, Lwiza K, Macdonald D, Petty C, Seaman J, Wainwright C (2019a) FCFA HyCRISTAL climate narrative rural infographic and brief. https://doi.org/10.5281/zenodo.3257288

Burgin L, Way C, Evans B, Rowell D, Marsham J, Semazzi F, Sabiiti G, Araujo J, Ascott M, Lapworth D, Macdonald D, Wainwright C (2019b) FCFA HyCRISTAL climate narrative urban infographic and brief. https://doi.org/10.5281/zenodo.3257301

Calow RC, MacDonald AM, Nicol AL, Robins NS (2010) Ground water security and drought in Africa: linking availability, access, and demand. Ground Water 48(2):246-256

Carter RC, Parker A (2009) Climate change, population trends and groundwater in Africa. Hydrol Sci J 54(4): 676-689

Cole MA, Elliott RJ, Strobl E (2014) Climate change, hydro-dependency, and the African Dam boom. World Dev 60:84-98

Conway D, Allison E, Felstead R, Goulden M (2005) Rainfall variability in East Africa: implications for natural resources management and livelihoods. Philos Trans R1 Soc Lond A Math Phys Eng Sci 363(1826):49-54

Di Baldassarre G, Montanari A, Lins H, Koutsoyiannis D, Brandimarte L, Blöschl G (2010) Flood fatalities in Africa: from diagnosis to mitigation. Geophys Res Lett 37(22)

Douglas I (2017) Flooding in African cities, scales of causes, teleconnections, risks, vulnerability and impacts. Int J Dis Risk Reduct 26:34 42 Available at: http://linkinghub.elsevier.com/retrieve/pii/S2212420917302595. Accessed 15 Dec 2017

Douglas I et al (2008) Unjust waters: climate change, flooding and the urban poor in Africa. Environ Urban 20(1):187-205 Available at: https://doi.org/10.1177/0956247808089156

Finney DL, Marsham JH, Jackson LS, Kendon EJ, Rowell DP, Boorman PM, Keane RJ, Stratton RA, Senior CA (2019) Implications of improved representation of convection for the East Africa water budget using a convection-permitting model. J Clim (in press)

Flato G, Marotzke J, Abiodun B, Braconnot P, Chou SC, Collins W, Cox P, Driouech F, Emori S, Eyring V, Forest C, Gleckler P, Guilyardi E, Jakob C, Kattsov V, Reason C, Rummukainen M (2013) Evaluation of climate models. In: Stocker TF, Qin D, Plattner G-K, Tignor M, Allen SK, Boschung J, Nauels A, Xia Y, Bex V, Midgley PM (eds) Climate change 2013: the physical science basis. Contribution of Working Group I to the Fifth Assessment Report of the Intergovernmental Panel on Climate Change. Cambridge University Press, Cambridge 
Garcìa VM, Suàrez MM (2013) Delphi method for expert consultation in scientific research. Rev Cubana Salùd Publ 39(2):253-267

Gowing J, Parkin G, Forsythe N, Walker D, Haile AT, Alamirew D (2016) Shallow groundwater in sub-Saharan Africa: neglected opportunity for sustainable intensification of small-scale agriculture? Hydrol Earth Syst Sci Discuss

Hecky RE, Bugenyi FWB, Ochumba P, Talling JF, Mugidde R, Gophen M, Kaufman L (1994) Deoxygenation of the deep water of Lake Victoria, East Africa. Limnol Oceanogr 39(6):1476-1481

Hillbruner C, Moloney G (2012) When early warning is not enough-lessons learned from the 2011 Somalia famine. Glob Food Secur 1:20-28. https://doi.org/10.1016/j.gfs.2012.08.001

Hunter PR (2003) Climate change and waterborne and vector-borne disease. J Appl Microbiol 94(s1):37-46 Available at: http://doi.wiley.com/10.1046/j.1365-2672.94.s1.5.x

Kamwamba-Mtethiwa J, Weatherhead K, Knox J (2016) Assessing performance of small-scale pumped irrigation systems in sub-Saharan Africa: evidence from a systematic review. Irrig Drain 65(3):308-318

Kashindye BB, (2015) Assessment of dagaa (Rastrineobola argentea) stocks and effects of environment in Lake Victoria, East Africa. Thesis. United Mations University, Fisheries Training Program. 58 pp.

Kendon EJ, Stratton RA, Tucker S, Marsham JH, Berthou S, Rowell DP, Senior CA (2019) Enhanced future changes in wet and dry extremes over Africa at convection-permitting scale. Nat Commun. https://oi. org/10.1038/s41467-019-09776-9

Kipkemboi J, van Dam AA, Mathooko JM, Denny P (2007) Hydrology and the functioning of seasonal wetland aquaculture-agriculture systems (Fingerponds) at the shores of Lake Victoria, Kenya. Aquac Eng 37(3): $202-214$

Kling H, Mugidde R (2014) Recent changes in the phytoplankton community of Lake Victoria in response to eutrophication. In: Hecky R, Munawar M (eds) The great lakes of the world (GLOW): food-web, health and integrity. Michigan State University Press, pp 47-66 Retrieved from http:/www.jstor.org/stable/10.14321/j. ctt1bqzmb5.9

LVFO Secretariat (2016) Lake Victoria fisheries management plan III. Available at: http://www.lvfo. org/sites/default/files/field/FISHERIES MANAGEMENT PLAN III (FMP III) FOR LAKE VICTORIA FISHERIES 2016 - 2020.pdf. Accessed 18 June 2018

MacDonald AM, Calow RC, Macdonald DMJ, Darling WG, O Dochartaigh BE (2009) What impact will climate change have on rural groundwater supplies in Africa? Hydrol Sci J 54(4):690-703. https://doi.org/10.1623 hysj.54.4.690

MacDonald AM, Bonsor HC, Dochartaigh BÉ, Taylor RG (2012) Quantitative maps of groundwater resources in Africa. Environ Res Lett 7(2):024009. https://doi.org/10.1088/1748-9326/7/2/024009

Marsham J, Rowell D, Evans B, Cornforth R, Semazzi F, Wilby R, Efitre J, Lwiza K, Ogutu-Ohwayo R (2015) First HyCRISTAL workshop - integrating hydroclimate science into policy decisions for climate-resilient infrastructure and livelihoods in East Africa. GEWEX Newsletter, 27, No4, 23-24 Available at: http://www. gewex.org/gewex-content/files_mf/1447702455Nov2015GEWEXNewsletter.pdf. Accessed 10 July 2010

McMichael AJ, Woodruff RE, Hales S (2006) Climate change and human health: present and future risks. Lancet 367(9513):859-869 https:/www.sciencedirect.com/science/article/pii/S0140673606680793. Accessed 14 June 2018

Meigh JR, McKenzie AA, Sene KJ (1999) A grid-based approach to water scarcity estimates for eastern and southern Africa. Water Resour Manag 13(2):85-115

Mueller ND, Gerber JS, Johnston M, Ray DK, Ramankutty N, Foley JA (2012) Closing yield gaps through nutrient and water management. Nature 490(7419):254

Muyanga M, Jayne TS (2014) Effects of rising rural population density on smallholder agriculture in Kenya. Food Policy 48:98-113 https://doi.org/10.1016/j.foodpol.2014.03.001

Nakawuka P, Langan S, Schmitter P, Barron J (2017) A review of trends, constraints and opportunities of smallholder irrigation in East Africa. Glob Food Secur. In press. https://doi.org/10.1016/j.gfs.2017.10.003

Niang I, Ruppel OC, Abdrabo MA, Essel A, Lennard C, Padgham J, Urquhart P (2014) Africa. In: Barros VR, Field CB, Dokken DJ, Mastrandrea MD, Mach KJ, Bilir TE et al (eds) Climate change 2014: impacts, adaptation, and vulnerability. Part B: regional aspects. Contribution of working group II to the fifth assessment report of the intergovernmental panel of climate change. Cambridge University Press, Cambridge, pp 1199-1265

Nicholson SE (2017) Climate and climatic variability of rainfall over eastern Africa. Rev Geophys 55. https://doi. org/10.1002/2016RG000544

Orindi VA, Murray LA (2005) Adapting to climate change in East Africa: a strategic approach (No. 117). International Institute for Environment and Development

Owor M, Taylor RG, Tindimugaya C, Mwesigwa D (2009) Rainfall intensity and groundwater recharge: empirical evidence from the Upper Nile Basin. Environ Res Lett 4:035009. https://doi.org/10.1088/17489326/4/3/035009 
Paerl HW, Huisman J (2008) Blooms like it hot. Science 320(5872):57-58

Patz JA et al (2005) Impact of regional climate change on human health. Nature 438(7066):310-317

Riahi K, Rao S, Krey V et al (2011) RCP 8.5-a scenario of comparatively high greenhouse gas emissions. Clim Chang 109:33. https://doi.org/10.1007/s10584-011-0149-y

Rowell DP (2019) An observational constraint on CMIP5 projections of the East African Long Rains and Southern Indian Ocean warming. Geophys Res Lett. https://doi.org/10.1029/2019GL082847

Rowell DP, Chadwick R (2018) Causes of the uncertainty in projections of tropical terrestrial rainfall change: East Africa. J Clim 31:5977-5995

Rowell DP, Booth BBB, Nicholson SE, Good P (2015) Reconciling past and future rainfall trends over East Africa. J Clim 28:9768-9788

Salami A, Kamara AB, Brixiova Z (2010) Smallholder agriculture in East Africa: trends, constraints and opportunities, Working Papers Series $\mathrm{N}^{\circ} 105$ African Development Bank, Tunis, Tunisia. Available at: https:/www.afdb.org/en/documents/document/working-paper-105-smallholder-agriculture-in-east-africatrends-constraints-and-opportunities-20266/. Accessed 10 July 2018

Seehausen O, Van Alphen JJM, Witte F (1997) Cichlids diversity threatened by eutrophication that curbs sexual selection. Science 277:1808-1811

Sillmann J, Kharin VV, Zhang X, Zwiers FW, Bronaugh D (2013) Climate extremes indices in the CMIP5 multimodel ensemble: part 1. Model evaluation in the present climate. J Geophys Res Atmos 118:17161733. https://doi.org/10.1002/jgrd.50203

Taylor RG, Koussis AD, Tindimugaya C (2009) Groundwater and climate in Africa - a review. Hydrol Sci J 54(4):655-664

Taylor KE, Stouffer RJ, Meehl GA (2012) An overview of CMIP5 and the experiment design. Bull Am Meteorol Soc 93:485-498

Taylor RG et al (2013a) Ground water and climate change. Nat Clim Chang 3(4):322-329. https://doi. org/10.1038/nclimate1744

Taylor RG, Todd MC, Kongola L, Maurice L, Nahozya E, Sanga H, MacDonald AM (2013b) Evidence of the dependence of groundwater resources on extreme rainfall in East Africa. Nat Clim Chang 3(4):374-378. https://doi.org/10.1038/nclimate1731

Taylor CM, Belušić D, Guichard F, Parker DJP, Vischel T, Bock O et al (2017) Frequency of extreme Sahelian storms tripled since 1982 in satellite observations. Nature 544:475-478. https://doi.org/10.1038/nature2

Tesfaye K, Gbegbelegbe S, Cairns JE, Shiferaw B, Prasanna BM, Sonder K, Boote KJ, Makumbi D, Robertson R (2015) Maize systems under climate change in sub-Saharan Africa: potential impacts on production and food security. Int J Clim Chang Strateg Manag 7:247-271

Thornton PK, Ericksen PJ, Herrero M, Challinor AJ (2014) Climate variability and vulnerability to climate change: a review. Glob Chang Biol 3313-3328

Uganda Vision (2040) http://npa.ug/uganda-vision-2040/. Accessed 27 June 2018

UN-DESA. United Nations, Department of Economic and Social Affairs, Population Division (2018) World urbanization prospects: the 2018 revision, custom data acquired via website. Available at https://esa.un. org/unpd/wup/DataQuery/. Accessed 26 June 2018

Williams TO (2015) Reconciling food and water security objectives of MENA and sub-Saharan Africa: is there a role for large-scale agricultural investments? Food Secur 7(6):1199-1209

Yang W, Seager R, Ma C, Lyon B (2015) The annual cycle of the east African precipitation. J Clim 28(6):23852404. https://doi.org/10.1175/JCLI-D-14-00484.1

You L, Ringler C, Wood-Sichra U, Robertson R, Wood S, Zhu T, Nelson G, Guo Z, Sun Y (2011) What is the irrigation potential for Africa? A combined biophysical and socioeconomic approach. Food Policy 36(6): $770-782$

Publisher's note Springer Nature remains neutral with regard to jurisdictional claims in published maps and institutional affiliations. 


\section{Affiliations}

F. Jorge Bornemann ${ }^{1} \cdot$ David P. Rowell ${ }^{1} \cdot$ Barbara Evans $^{2} \cdot$ Dan J. Lapworth ${ }^{3}$. Kamazima Lwiza ${ }^{4}$ • David M.J. Macdonald ${ }^{3}$ • John H. Marsham ${ }^{2,5} \cdot$ Kindie Tesfaye $^{6}$. Matthew J. Ascott ${ }^{3} \cdot$ Celia Way ${ }^{2}$

1 Met Office Hadley Centre, Fitzroy Road, Exeter EX1 3PB, UK

2 University of Leeds, Leeds, UK

3 British Geological Survey, Wallingford, UK

4 Stony Brook University, New York, NY, USA

5 National Centre for Atmospheric Science (NCAS), Leeds, UK

6 International Maize and Wheat Improvement Center (CIMMYT), Addis Ababa, Ethiopia 